\title{
Influenza vaccination during pregnancy and influencing factors in Korea: A multicenter questionnaire study of pregnant women and obstetrics and gynecology doctors
}

\author{
Byung Soo Kang ${ }^{1}$, San Ha Lee ${ }^{1}$, Woo Jeng Kim', Jeong Ha Wie², In Yang Park and Hyun Sun Ko ${ }^{1^{*}}$ (D
}

\begin{abstract}
Background: Although the World Health Organization and health authorities in most countries recommend that pregnant women receive inactivated influenza virus vaccines, coverage remains low. This study aimed to investigate (1) the proportion of pregnant women who received an influenza vaccination and influencing factors and (2) the proportion of obstetrics and gynecology (OBGYN) doctors who routinely recommend influenza vaccination to pregnant women and influencing factors.
\end{abstract}

Methods: Two separate, anonymized questionnaires were developed for physicians and pregnant and postpartum women and were distributed to multicenters and clinics in South Korea. The proportions of women who received influenza vaccination during pregnancy and OBGYN doctors who routinely recommend the influenza vaccine to pregnant women were analyzed. Independent influencing factors for both maternal influenza vaccination and OBGYN doctors' routine recommendations to pregnant women were analyzed using log-binomial regression analysis.

Results: The proportion of self-reported influenza vaccination during pregnancy among 522 women was $63.2 \%$. Pregnancy-related independent factors influencing maternal influenza vaccination were "(ever) received information about influenza vaccination during pregnancy" (OR 8.9, 95\% Cl 4.17-19.01), "received vaccine information about from OBGYN doctors" (OR 11.44, 95\% Cl 5.46-24.00), "information obtained from other sources" (OR 4.38, 95\% Cl 2.01-9.55), and "second/third trimester" (OR 2.41,95\% Cl 1.21-4.82)..

Among 372 OBGYN doctors, $76.9 \%$ routinely recommended vaccination for pregnant women. Independent factors effecting routine recommendation were "working at a private clinic or hospital" (OR 5.33, 95\% Cl 2.44-11.65), "awareness of KCDC guidelines" (OR 3.11, 95\% Cl 1.11-8.73), and "awareness of the 2019 national free influenza vaccination program for pregnant women" (OR 4.88, 95\% Cl 2.34-10.17). OBGYN doctors most commonly chose 'guidelines proposed by the government or public health $(108,46 \%)$ and academic committees $(59,25 \%)$, as a factor which expect to affect the future recommendation

\footnotetext{
*Correspondence: mongkoko@catholic.ac.kr

1 Department of Obstetrics and Gynecology, Seoul St. Mary's Hospital,

College of Medicine, The Catholic University of Korea, Seoul, Republic

of Korea

Full list of author information is available at the end of the article
}

(C) The Author(s) 2021. Open Access This article is licensed under a Creative Commons Attribution 4.0 International License, which permits use, sharing, adaptation, distribution and reproduction in any medium or format, as long as you give appropriate credit to the original author(s) and the source, provide a link to the Creative Commons licence, and indicate if changes were made. The images or other third party material in this article are included in the article's Creative Commons licence, unless indicated otherwise in a credit line to the material. If material is not included in the article's Creative Commons licence and your intended use is not permitted by statutory regulation or exceeds the permitted use, you will need to obtain permission directly from the copyright holder. To view a copy of this licence, visit http://creativecommons.org/licenses/by/4.0/. The Creative Commons Public Domain Dedication waiver (http://creativeco mmons.org/publicdomain/zero/1.0/) applies to the data made available in this article, unless otherwise stated in a credit line to the data. 
Conclusion: This study showed that providing information about maternal influenza vaccination, especially by OBGYN doctors, is crucial for increasing vaccination coverage in pregnant women. Closer cooperation between the government and OBGYN academic societies to educate OBGYN doctors might enhance routine recommendations.

Keywords: Influenza, Maternal, Vaccination

\section{Background}

Compared with the general population, pregnant women are at high risk for influenza-related complications due to their altered immunity and increased cardiopulmonary burden [1, 2]. During the 2009 H1N1 influenza pandemic season, maternal influenza infection was associated with severe complications resulting in maternal death and admission to intensive care units [3]. Additionally, influenza vaccines are not licensed for use in infants younger than six months. Therefore, infants younger than six months cannot be protected except through maternal immunization. According to global statistics, approximately 228,000 (95\% Confidence Interval (CI) 150,000-344,000) of annual hospitalizations of infants younger than six months were associated with influenza [4]. Furthermore, infants younger than six months with confirmed influenza infection were at highest risk for hospitalization due to neurologic or pulmonary complications and, thus, for admission to an intensive care unit $[5,6]$. Several studies have demonstrated the effectiveness of maternal influenza vaccination for protecting infants younger than six months from influenza, respiratory infection, and severe pneumonia $[7,8]$.

Although the World Health Organization (WHO) and health authorities in most countries recommend pregnant women receive a vaccination with inactivated influenza virus [9-11], vaccination coverage is not sufficient. Influenza vaccination rates in people aged 65 years or older, which is an indicator of annual influenza vaccination in the Organization for Economic Cooperation and Development (OECD) countries, were less than $60 \%$ in most countries, although it was over $80 \%$ in Korea [12]. Since 2012, the Korean Centers for Disease Control and Prevention (KCDC) has recommended vaccinating pregnant women as well as women contemplating pregnancy during the flu season under the Guidelines of Vaccination for Adults [13]. However, it has been reported that the vaccination rate associated with pregnancy was less than $40 \%[14,15]$. A national free immunization program for influenza was developed for pregnant women to increase vaccine coverage during the 2019-2020 flu season in Korea. This study aimed to investigate 1) the proportion of pregnant women who received an influenza vaccination and influencing factors and 2) the proportion of obstetrics and gynecology (OBGYN) doctors who routinely recommend influenza vaccination for pregnant women and their influencing factors.

\section{Methods \\ Study population and recruitment}

The survey was conducted from October 15, 2019, to December 31, 2019. The questionnaires for pregnant women were completed during routine antenatal care visits at a mix of 30 public and private clinics or hospitals located in metropolitan areas and the eight provinces of South Korea. Medical doctors or trained assistants distributed either a paper form or an online link to the survey in Google forms in person via opportunistic sampling at antenatal clinics or wards. Questionnaires for physicians were distributed to medical doctors registered with the Korean Society of Maternal-Fetal Medicine (KSMFM), Korean Society of Perinatal Medicine (KSPM), Korean Association of Obstetrics and Gynecology (KAOG), or Korean Society of Ultrasound in Obstetrics and Gynecology (KSUOG) via a paper form or an online link to the survey in Google forms by e-mail. Participation in this survey was voluntary, and no financial or other incentives were offered. Response to the survey implied consent. Information provided by the participants was voluntary and possibly incomplete.

\section{Survey questionnaires}

Two questionnaires were developed and used anonymously to survey pregnant or postpartum women and OBGYN doctors (Suppl. 1 \& 2). The questionnaires were adapted from previously self-administered questionnaires [16-18] composed by a multidisciplinary study team that included OBGYN doctors, biomedical statisticians, and pregnant women. A pilot survey involving both target groups was conducted to ensure questionnaire comprehensiveness. Because some participants did not know that the national free influenza vaccination program in the 2019-2020 flu season included pregnant women, we added the response option "free vaccination program" to question 10-2 in the questionnaire.

The questionnaire for pregnant or postpartum women assessed the following characteristics: age, pregnancy duration, parity, natural conception or use of assisted reproduction, education level, occupation, and administrative district of residential areas. Inclusion 
criteria were pregnant women over six weeks' gestation with confirmed fetal heartbeat by ultrasonography and postpartum women within six weeks after delivery. The questionnaire for physicians queried the following characteristics: age, sex, recent maternity care, and characteristics of their employer, including whether their clinic or hospital is private or public and within which administrative district it is located. Residential areas and physicians' work locations were divided into metropolitan and non-metropolitan areas. Metropolitan areas included Seoul, Busan, Gwangju, Incheon, Ulsan, Daejeon, Sejong, and Kyunggi provinces around Seoul. Non-metropolitan areas included Chuncheon, Gyeongsang, Jeolla, Gangwon, and Jeju provinces.

Pregnant and postpartum women were asked the following: (1) whether they received influenza vaccination during pregnancy in the 2019-2020 flu season; (2) whether they received information about influenza vaccination; (3) information sources; (4) influenza vaccination during a previous pregnancy; (5) reasons for not receiving influenza vaccine; and (6) factors influencing future vaccination. The women were classified according to self-reported influenza vaccination status for the flu season of 2019-2020. Response options for questions (1), (2), and (4) were yes or no. Questions about information sources permitted multiple responses. If a response included OBGYN doctors with or without other sources, it was designated to "OBGYN doctors." If a response included other sources such as public health, media, friends, or family but not OBGYN doctors, the source was designated to "other sources."

OBGYN doctors were grouped according to whether they provided routine recommendations for the influenza vaccine for pregnant women based on an affirmative response to the question, "Do you recommend the influenza vaccine to pregnant women in your clinic?". OBGYN doctors who answered, "always recommend vaccination," were designated to the, "routine recommendation group," and OBGYN doctors who responded, "sometimes or never recommended vaccination," were designated to the, "passive recommendation group." Physician awareness of the 2019 national free influenza vaccination program for pregnant women and government recommendations such as "all pregnant or breastfeeding women during flu season are primarily recommended to receive an inactive influenza vaccine" was evaluated. Attitudes toward providing information about influenza vaccination for pregnant women were analyzed based on responses to the following questions: 1) "Do you provide information about influenza vaccination to pregnant women?" and 2) "Do you recommend influenza vaccination during pregnancy?".
Also, the survey sought to determine each physician's own influenza vaccination status during the previous flu season. Physicians were asked about influencing factors for future recommendations for influenza vaccination for pregnant women. Ethical approval was granted by the Institutional Review Board of The Catholic University of Korea (KC19QES10646).

\section{Sample size calculation}

The sample size for the survey of pregnant or postpartum women was calculated with the following assumptions: the proportion of women having received the influenza vaccine during pregnancy was $50 \%$, with a confidence interval of $95 \%$ and an alpha of 0.05 . The initial calculated minimum sample size was 384 participants. Given the nonresponse rate $(10 \%)$ and the incomplete responses rate (30\%), however, 538 pregnant women were recruited to meet the minimum sample size. The sample size for the survey of OBGYN doctors was calculated based on the estimation that $60 \%$ of OBGYN doctors routinely recommend influenza vaccination to pregnant women, with a $95 \%$ confidence interval and an alpha of 0.05 . Therefore, the minimum number of required OBGYN doctors was estimated at 360 . Given the $55 \%$ response rate, however, the minimum number of participants required was estimated as 640. Data collection was stopped when the minimum numbers of responses for the analyses were reached.

\section{Data analysis}

We performed all data analyses using SPSS (version 24.0; SPSS Inc., Chicago, IL, USA). Continuous variables of age of respondents and gestational weeks of pregnant women were presented as mean \pm standard deviation and compared using Student's t-test. All other variables were categorical data, which were expressed as number (\%) and compared using the Chi-square test. To assess influencing factors associated with vaccine uptake by pregnant women, we calculated the odds ratios (ORs) and 95\% CIs using log-binomial regression models. Variables with a significant cutoff, $\mathrm{p}<0.2$, between vaccinated and unvaccinated groups in univariate analyses were included in multivariate analyses, after adjustment for maternal age, residence, education, and occupation. Univariate analysis identified variables $(\mathrm{p}<0.2)$ with OBGYN doctors' routine recommendations for influenza vaccination between the routine and passive recommendation groups. After adjustment for physician age, sex, and location of clinic or hospital, significant variables were identified in multivariate analyses. Statistical significance was set at $\mathrm{p}<0.05$. 


\section{Results}

\section{Demographic characteristics of pregnant women}

A total of 522 questionnaires was eligible to be analyzed after excluding 34 incomplete questionnaires. The questionnaires were collected online $(10.2 \%, 53 / 522)$ or via paper survey $(89.8 \%, 487 / 522)$. The residential distribution of pregnant $(n=492)$ and postpartum women $(\mathrm{n}=30)$ is presented in Fig. 1(A) and Suppl. 3, which indicate that $80.8 \%$ of respondents lived in a metropolitan area.

The demographic characteristics associated with influenza vaccination are presented in Table 1 . There were significant differences in gestational age and pregnancy period between the two groups $(p=0.002$, for both). Women in the vaccinated group were significantly better informed about the influenza vaccine than were women in the unvaccinated group $(\mathrm{p}<0.001)$. Additionally, women in the vaccinated group were more likely to be informed about the vaccine by their OBGYN doctor than were women in the unvaccinated group $(\mathrm{p}<0.001)$. There were no significant differences in mean maternal age, parity, conception method, education, metropolitan residence, occupation, or influenza vaccination during the previous pregnancy.

\section{Influencing factors for maternal influenza vaccination}

In univariate analyses, "ever received information about influenza vaccination during pregnancy," "received vaccine information from OBGYN doctor or other sources," and "second/third trimester" were significantly associated with maternal influenza vaccination
(Table 2). In multivariate analyses adjusted for maternal age, education, occupation, location of residence, and pregnancy period, "ever received information about influenza vaccination during pregnancy" (OR 8.9, 95\% CI 4.17-19.01), "received vaccine information about from OBGYN doctors" (OR 11.44, 95\% CI 5.46-24.00), "information obtained from other sources" (OR 4.38, 95\% CI 2.01-9.55), and "second/third trimester" (OR $2.41,95 \%$ CI 1.21-4.82) significantly increased the odds for influenza vaccination.

\section{Barriers against influenza vaccination and factors associated with future vaccination}

Among 192 women in the unvaccinated group, 169 (88\%) responded to the question about reasons for not receiving the influenza vaccine ("Why did you not receive the influenza vaccination?"). Fifty-nine (34.9\%) respondents replied, "I did not know if I should be vaccinated," and 37 (21.9\%) answered, "I am planning to be vaccinated according to the appropriate vaccination schedule." Seventy-three (43.2\%) respondents replied, "I did not want to have the influenza vaccination." Participants who responded that they did not want to be vaccinated were asked their reason, and all respondents $(\mathrm{n}=73)$ answered that they "did not know the importance of vaccination" (Table 3 ).

Among 192 women included in the unvaccinated group, 92 responded to the question about influencing factors for future vaccination, and multiple responses were allowed ("If you did not know the importance of

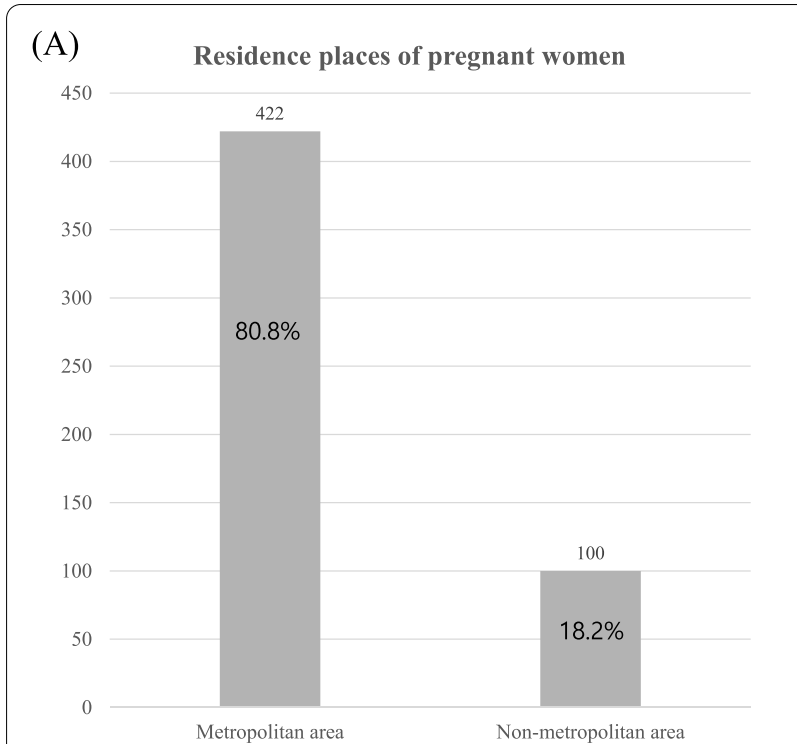

(B)

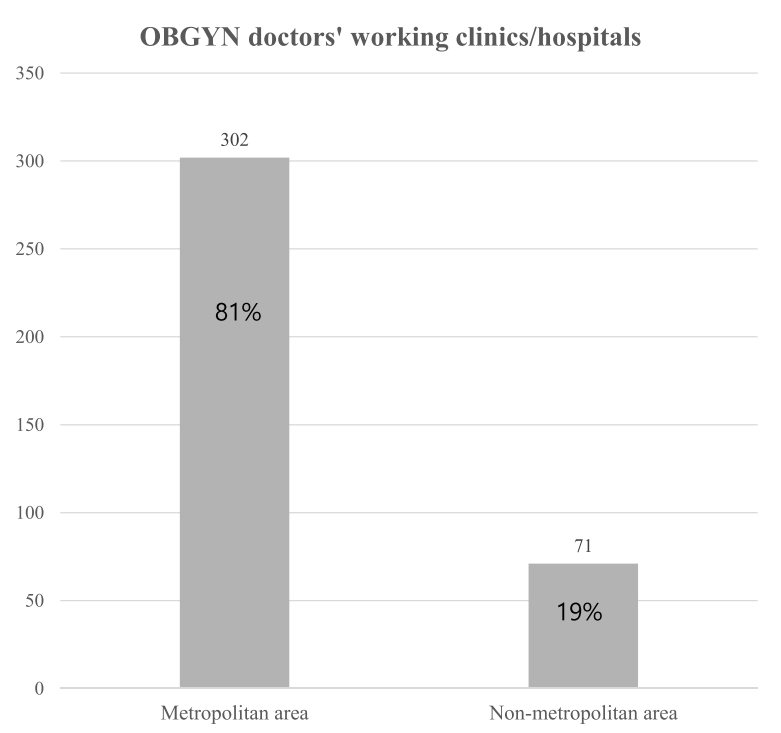

Fig. 1 Distributions of respondents. (A) Residences of pregnant women $(n=522)$ (B) OBGYN ${ }^{\mathrm{a}}$ doctors working clinics/hospitals $(n=383)$. aOBGYN: obstetrics and gynecology. This file 'South Korea location map' by NordNordWest in Supplement 3 for presenting metropolitin and non-metropolitan area is licensed under CC BY-SA 3.0 < https://creativecommons.org/licenses/by-sa/3.0 >, via Wikimedia Commons. 
Table 1 Demographic characteristics of pregnant or postpartum women

\begin{tabular}{|c|c|c|c|}
\hline Characteristics & Vaccinated $(n=330)$ & Unvaccinated $(n=192)$ & $p$-value \\
\hline Maternal age (yrs) (mean \pm SD) & $33.32 \pm 3.85$ & $33.18 \pm 4.53$ & 0.069 \\
\hline Gestational age (weeks) (mean $\pm S D)$ & $31.28 \pm 20.27$ & $26.31 \pm 9.12$ & 0.002 \\
\hline Pregnancy period & & & 0.002 \\
\hline$\leq 13$ weeks $(n, \%)$ & $17(5.2)$ & $25(13.0)$ & \\
\hline 14-27 weeks (n, \%) & $67(20.3)$ & $45(23.4)$ & \\
\hline$\geq 28$ weeks $(n, \%)$ & $230(69.7)$ & $108(56.3)$ & \\
\hline Postpartum (n, \%) & $16(4.8)$ & $14(7.3)$ & \\
\hline Nulliparous women (n, \%) & $219(66.4)$ & $122(63.5)$ & 0.514 \\
\hline Assisted reproduction (n, \%) & $29(6.6)$ & $19(9.9)$ & 0.790 \\
\hline Education (college degree or higher) (n, \%) & $304(92.1)$ & $168(87.5)$ & 0.084 \\
\hline Metropolitan residence $(n, \%)$ & $270(81.8)$ & $15(79.2)$ & 0.458 \\
\hline Occupation & & & 0.186 \\
\hline Housewife (n, \%) & $145(43.9)$ & $73(38.0)$ & \\
\hline Other than housewife $(n, \%)$ & $185(56.1)$ & $119(62.0)$ & \\
\hline Ever received information about influenza vaccination during pregnancy $(n, \%)$ & $321(97.3)$ & $155(80.7)$ & $<0.001$ \\
\hline Source of information & & & $<0.001$ \\
\hline OBGYNª doctor (n, \%) & $239(72.4)$ & $83(43.2)$ & \\
\hline Non-OBGYN doctors, public health care, media, friends, or family ( $n, \%)$ & $91(27.6)$ & $109(56.8)$ & \\
\hline Influenza vaccination in a previous pregnancy $(n, \%)^{b}$ & $71(64.5)$ & $34(54.8)$ & 0.205 \\
\hline
\end{tabular}

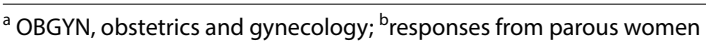

Values are presented as mean \pm standard deviation or $\mathrm{n}(\%)$

vaccination, in which cases would you get the vaccination?"). The 92 women who responded provided 122 choices. The majority of the respondents $(\mathrm{n}=81,88 \%)$ said that they would get the influenza vaccine in the future if their obstetrician recommended it.

Table 2 Associated factors for maternal influenza vaccination among pregnant or postpartum women

\begin{tabular}{|c|c|c|c|c|c|c|}
\hline \multirow[t]{2}{*}{ Factors } & \multicolumn{3}{|l|}{ Univariate } & \multicolumn{3}{|l|}{ Multivariate } \\
\hline & Crude OR & $95 \% \mathrm{Cl}^{\mathrm{b}}$ & p-value & Adjusted OR & $95 \% \mathrm{Cl}$ & $p$-value \\
\hline \multicolumn{7}{|c|}{ Ever received information about influenza vaccination } \\
\hline No & 1 & & & 1 & & \\
\hline Yes & 8.51 & $4.01-18.08$ & $<0.001$ & $8.9^{c}$ & $4.17-19.01$ & $<0.001$ \\
\hline \multicolumn{7}{|l|}{ Source of information } \\
\hline No & 1 & & & 1 & & \\
\hline $\begin{array}{l}\text { Non-OBGYN }{ }^{d} \text { doctors, public health care, } \\
\text { media, friends, and family }\end{array}$ & 4.37 & $2.02-9.44$ & $<0.001$ & $4.38^{c}$ & $2.01-9.55$ & $<0.001$ \\
\hline OBGYN doctor & 11.45 & $5.49-23.87$ & $<0.001$ & $11.44^{\mathrm{C}}$ & $5.46-24.00$ & $<0.001$ \\
\hline \multicolumn{7}{|l|}{ Pregnancy period } \\
\hline $1^{\text {st }}$ trimester & 1 & & & 1 & & \\
\hline $2^{\text {nd }}$ or $3^{\text {rd }}$ trimester or postpartum & 2.76 & $1.45-5.25$ & 0.002 & $2.41^{\mathrm{e}}$ & $1.21-4.82$ & 0.013 \\
\hline \multicolumn{7}{|c|}{ Influenza vaccination in previous pregnancy } \\
\hline No & 1 & & & & & \\
\hline Yes & 1.25 & $0.80-1.96$ & 0.321 & & & \\
\hline
\end{tabular}

${ }^{\mathrm{a}} \mathrm{OR}$, odds ratio; ${ }^{\mathrm{b}} \mathrm{Cl}$, confidence interval

c Adjusted for maternal age, education, occupation, location of residence, and pregnancy period

d OBGYN, obstetrics and gynecology

${ }^{\mathrm{e}}$ Adjusted for maternal age, education, occupation, location of residence, and other covariates 
Table 3 Reasons for not wanting an influenza vaccination in unvaccinated women and factors for future vaccination during pregnancy

\begin{tabular}{ll}
\hline $\begin{array}{l}\text { Reasons for not wanting influenza vaccination in unvaccinated } \\
\text { women (multiple responses) (Total responders, } \boldsymbol{n = 7 3 )}\end{array}$ \\
\hline Not knowing the importance of vaccine & $48(66 \%)$ \\
Not knowing the importance of vaccine + Distrust of effect & $1(1 \%)$ \\
Not knowing the importance of vaccine + Fear of side effects & $1(1 \%)$ \\
Not knowing the importance of vaccine + Others & $23(32 \%)$ \\
Major influencing factors for future vaccination during pregnancy \\
(multiple responses) (Total responders, $n=92)$ \\
OBGYNa doctors & $81(88 \%)$ \\
Other medical doctors ${ }^{b}$ & $4(2.1 \%)$ \\
Family or friends & $4(2.1 \%)$ \\
TV/radio/paper/internet & $9(9.8 \%)$ \\
Free vaccination program & $16(17.4 \%)$ \\
Pediatric doctors & $8(8.7 \%)$
\end{tabular}

${ }^{\mathrm{a}}$ OBGYN, obstetrics and gynecology; ${ }^{\mathrm{b}}$ Other medical doctors, medical doctors other than OBGYN or pediatric doctors

\section{Demographic characteristics, awareness, and attitudes of OBGYN doctors}

A total of 373 questionnaires was eligible to be analyzed after excluding three incomplete questionnaires and 86 responses from non-OBGYN doctors. Questionnaires were collected through an online survey $(88.7 \%$, $331 / 373)$ or a paper survey $(11.3 \%, 42 / 373)$. As shown in Fig. 1(B) and Suppl. 3, the distribution of OBGYN doctors' clinics or hospitals suggests that $80.5 \%$ of respondents worked in metropolitan areas, with $37.8 \%$ in Seoul and $43.2 \%$ in Gyeonggi and other metropolitan cities. Demographic characteristics, awareness, and attitudes are presented in Table 4. A total of 287 (76.9\%) of the 373 OBGYN doctors was included in the routine recommendation group. Significant differences were found between routine and passive recommendation groups, including 1) affiliation with a private clinic or hospital; 2) personal influenza vaccination in the previous year; 3) provided maternity care within the last five years; 4) awareness of KCDC guidelines; 5) agreement with the recommendations for influenza vaccine during pregnancy; 6) appropriate time for influenza vaccination during pregnancy; and 7) awareness of the 2019 national free influenza vaccination program for pregnant women.

\section{Influencing factors for influenza vaccine recommendation by OBGYN doctors}

In univariate analysis, "working at a private clinic or hospital", "provided maternity care within the last 5 years", "received influenza vaccination in the previous year", "awareness of KCDC guidelines", and "awareness of the 2019 national free influenza vaccination program" were significantly associated with routine vaccine recommendation by OBGYN doctors (Table 5). In a multivariate analysis, "working at a private clinic or hospital" (OR 5.33, 95\% CI 2.44-11.65), "awareness of KCDC guidelines" (OR 3.11, 95\% CI 1.11-8.73), and "awareness of the 2019 national free influenza vaccination program

Table 4 Demographic characteristics, awareness, and attitudes of OBGYNa doctors associated with recommendations of maternal influenza vaccination

\begin{tabular}{|c|c|c|c|}
\hline Characteristics & $\begin{array}{l}\text { Routine recommendation } \\
\text { group }(n=287)\end{array}$ & $\begin{array}{l}\text { Passive recommendation } \\
\text { group }(\mathrm{n}=86)\end{array}$ & p-value \\
\hline Age (years) (mean $\pm S D)$ & $47.51 \pm 9.4$ & $45.76 \pm 12.52$ & 0.231 \\
\hline Female $(n, \%)$ & $154(53.7)$ & $54(62.8)$ & 0.135 \\
\hline Private clinic/hospital (n, \%) & $263(91.6)$ & $54(62.8)$ & $<0.001$ \\
\hline Metropolitan area $(n, \%)$ & $231(80.5)$ & $71(82.6)$ & 0.668 \\
\hline Provided maternity care within the last 5 years (n, \%) & $259(90.2)$ & $68(79.1)$ & 0.006 \\
\hline Received influenza vaccination in the previous year (n, \%) & $272(94.8)$ & $71(82.6)$ & $<0.001$ \\
\hline $\begin{array}{l}\text { Awareness of safety, importance, and priority groups of vaccination before, dur- } \\
\text { ing, and after delivery, recommended by } \operatorname{KCDC}^{\mathrm{b}} \text { guidelines }(n, \%)\end{array}$ & $278(96.9)$ & $68(79.1)$ & $<0.001$ \\
\hline Do you provide information about influenza vaccine to pregnant women? & & & $<0.001$ \\
\hline $\begin{array}{l}\text { Always }(n, \%) \\
\text { Sometimes }(n, \%) \\
\text { No }(n, \%)\end{array}$ & $\begin{array}{l}276(96.2) \\
11(3.8) \\
0(0)\end{array}$ & $\begin{array}{l}8(9.3) \\
61(70.9) \\
17(19.8)\end{array}$ & \\
\hline $\begin{array}{l}\text { Appropriate time for influenza vaccination related to pregnancy }{ }^{c}(n, \%) \\
\text { All trimesters, pre-pregnancy, and postpartum } \\
2^{\text {nd }} \text { and } 3^{\text {rd }} \text { trimesters, pre-pregnancy, and postpartum } \\
2^{\text {nd }} \text { and } 3^{\text {rd }} \text { trimesters and postpartum }\end{array}$ & $\begin{array}{l}158(70.2 \%) \\
61(27.1 \%) \\
6(2.7 \%)\end{array}$ & $\begin{array}{l}33(49.3 \%) \\
26(38.8 \%) \\
8(11.9 \%)\end{array}$ & 0.001 \\
\hline Awareness about 2019 pregnant women free vaccination $(n, \%)$ & $268(93.4)$ & $51(59.3)$ & $<0.001$ \\
\hline
\end{tabular}

${ }^{\mathrm{a}}$ OBGYN, obstetrics and gynecology; ${ }^{\mathrm{b}} \mathrm{KCDC}$, Korean Centers for Disease Control and Prevention; ${ }^{\mathrm{C}} \mathrm{A}$ total of 292 OBGYN doctors responded to this question 
Table 5 Associated factors for routine vaccine recommendation among respondent OBGYNa doctors

\begin{tabular}{|c|c|c|c|c|c|c|c|c|}
\hline \multirow[t]{2}{*}{ Factors } & \multicolumn{5}{|c|}{ Univariate analysis } & \multicolumn{3}{|l|}{ Multivariate analysis } \\
\hline & Crude $O R^{b}$ & & $95 \% \mathrm{Cl}^{\mathrm{c}}$ & p-value & & Adjusted OR ${ }^{\mathrm{e}}$ & $95 \% \mathrm{Cl}$ & p-value \\
\hline \multicolumn{9}{|l|}{ Work place } \\
\hline $\begin{array}{l}\text { Public office/ } \\
\text { hospital }\end{array}$ & 1 & & & & 1 & & & \\
\hline $\begin{array}{l}\text { Private clinic/ } \\
\text { hospital }\end{array}$ & 6.49 & $3.55-11.89$ & & $<0.001$ & 5.33 & $2.44-11.65$ & & $<0.001$ \\
\hline \multicolumn{9}{|c|}{ Provided maternity care within the last 5 years } \\
\hline No & 1 & & & & 1 & & & \\
\hline Yes & 2.45 & $1.28-4.69$ & & 0.007 & 1.66 & $0.74-3.70$ & & 0.216 \\
\hline \multicolumn{9}{|c|}{ Received influenza vaccination in the previous year } \\
\hline No & 1 & & & & 1 & & & \\
\hline Yes & 3.83 & $1.79-8.21$ & & 0.001 & 2.56 & $0.96-6.81$ & & 0.061 \\
\hline \multicolumn{9}{|c|}{ Awareness of safety, importance, and priority groups of vaccination before, during, and after delivery, as recommended by $\mathrm{KCDC}^{\mathrm{d}}$ guidelines } \\
\hline No & 1 & & & & 1 & & & \\
\hline Yes & 8.18 & $3.52-18.99$ & & $<0.001$ & 3.11 & $1.11-8.73$ & & 0.031 \\
\hline \multicolumn{9}{|c|}{ Awareness about 2019 national free influenza vaccination program } \\
\hline No & 1 & & & & 1 & & & \\
\hline Yes & 9.68 & $5.14-18.24$ & & $<0.001$ & 4.88 & $2.34-10.17$ & & $<0.001$ \\
\hline
\end{tabular}

for pregnant women" (OR 4.88, 95\% CI 2.34-10.17) were associated with routine recommendation. However, "provided maternity care within the last 5 years" and "received influenza vaccination in the previous year" were not significant in the multivariate model.

Factors expected to effect OBGYN future recommendations for maternal influenza vaccination (multiple responses)

Among 235 choices from 217 respondents, guidelines recommended by the government or public health (108, $46 \%)$ and academic committees $(59,25 \%)$ were endorsed as major factors influencing OBGYN doctors' future recommendations for maternal influenza vaccination. Other factors included academic papers and lectures $(31,13 \%)$, media advertisements $(28,12 \%)$, and free vaccination $(9,4 \%)$.

\section{Discussion}

In this study, $63.2 \%$ of respondent pregnant women were vaccinated against influenza, and $76.9 \%$ of respondent OBGYN doctors routinely recommended the influenza vaccine for pregnant women. Univariate and multivariate analyses showed that having ever received information about influenza vaccination during pregnancy, especially from OBGYN doctors, and second/ third trimester were associated with influenza vaccination in pregnant women. The most significant barrier to influenza vaccination among pregnant women was a lack of awareness. In the survey for OBGYN doctors, independent factors effecting routine recommendation were working at a private clinic or hospital, awareness of KCDC guidelines, and awareness of the national free influenza vaccination program for pregnant women during the 2019 flu season.

Pregnancy-related vaccination rates in the US were between $49.1 \%$ and $53.6 \%$ from 2015 to 2018 [19]. In Ireland, the highest vaccination rates reported in pregnant women were $62 \%$ and $58 \%$ during the $2017-18$ and $2016-$ 2017 flu seasons, respectively [20]. The highest vaccination rate during pregnancy in Western Australia was 61\% in 2015 [21]. Previous questionnaire studies from Korea reported $35 \%-40 \%$ vaccination rates in pregnant women $[14,15]$. However, vaccination coverage for the total pregnant population of Korea was unknown until the 2018-2019 flu season because influenza vaccination was not covered by insurance and was performed in private settings. We speculate that the national free influenza vaccination program, which was initiated for the 20192020 flu season in Korea, might have increased awareness of vaccination and confidence among OBGYN doctors, which could lead to enhanced routine recommendations for pregnant women. A previous study of Korean obstetricians about maternal influenza vaccination reported that only $26.5 \%$ of obstetricians strongly recommended maternal influenza vaccination [22]. It is well known that advice and encouragement from familiar healthcare 
professionals (HCPs) significantly improve vaccine acceptance in pregnant women [23]. Additionally, several studies have shown that HCP knowledge about vaccine efficacy and safety is significantly associated with their vaccine recommendations. HCP confidence about vaccination is crucial for vaccination implementation in pregnant women [24-26]. Because OBGYN doctors are most familiar with the conditions of pregnant women, the professional information and recommendations they provide can affect directly vaccination decisions. Because most of the OBGYN doctors in the present study considered vaccination guidelines an important factor for future recommendations, further education on existing guidelines and supporting position statements or programs by academic committees, especially those related to maternal-fetal medicine, could increase routine recommendations by OBGYN doctors by increasing confidence in their recommendations. Previous similar studies about maternal influenza vaccination with influencing factors were performed in only a few centers [15-19], so it is important to note that this study was performed across all provinces of Korea.

This study has several limitations. First, although this study included all provinces of Korea to maximize the demographic diversity of the study populations, it cannot be considered representative of all pregnant women and OBGYN doctors in Korea. Second, responding doctors and hospitals might have had positive attitudes toward vaccination, introducing the possibility of a selection bias, which could explain why our sample had nearly double the proportion of maternal influenza vaccination than that observed in previous Korean studies. Third, self-reported vaccination status might have introduced a potential reporting bias in our estimation. In addition, the number of non-respondents among the surveyed pregnant women and OBGYN doctors was not recorded. Finally, the cross-sectional nature of this study, rather than a prospective study, can be a limitation.

This study also has several strengths. First, our study included a significant number of respondents who lived or worked not only in metropolitan areas, but also respondents who lived or worked in non-metropolitan areas. Although the proportion of respondents who lived in local provinces was only about $20 \%$, it correlated with the percentage of live births in local provinces, which was about $30 \%$ of all births in Korea [27]. Among the pregnant respondents, there was no significant difference in terms of residential distribution between the vaccinated and unvaccinated groups. Also, the effect of physician workplace location on routine versus passive recommendation was not significant. Second, the surveys of pregnant or postpartum women and OBGYN doctors were conducted anonymously, allowing free expression of opinions by the respondents. Most importantly, our study found a more than twice as large of a proportion of OBGYN doctors who routinely recommend maternal influenza vaccination compared with those in previous similar studies, which was correlated with a significantly increased proportion of maternal influenza vaccination.

\section{Conclusion}

In this study, the proportion of pregnant women who reported receiving an influenza vaccination was $63.2 \%$, and the proportion of OBGYN doctors who routinely recommended influenza vaccination was $76.9 \%$. This study showed that providing information about maternal influenza vaccination, especially by OBGYN doctors, is crucial for increasing vaccination coverage in pregnant women. The 2019 national free influenza vaccination program in Korea facilitated recommendations of maternal influenza vaccination by OBGYN doctors. Based on the high acceptance rates for preventive vaccines in Korea [28, 29], the maternal influenza vaccination program could be more successful with provision of the appropriate information. Close cooperation between the KCDC and OBGYN academic societies is crucial for enhancing the confidence of OBGYN doctors and their recommendations to increase influenza vaccination during pregnancy, which will maximize the benefits of the vaccine for both mothers and infants.

\section{Abbreviations}

OBGYN: Obstetrics and gynecology; OECD: Organization for Economic Cooperation and Development; WHO: World Health Organization; KCDC: Korean Centers for Disease Control and Prevention; KSMFM: Korean society of Maternal-Fetal Medicine; KSPM: Korean Society of Perinatal Medicine; KAOG: Korean Association of Obstetrics and Gynecology; KSUOG: Korean Society of Ultrasound in Obstetrics and Gynecology; HCP: Healthcare professional.

\section{Supplementary Information}

The online version contains supplementary material available at https://doi. org/10.1186/s12884-021-03984-2.

Additional file 1. Questionnaire. Survey of pregnant or postpartum women: vaccination during pregnancy.

Additional file 2. Questionnaire. Survey of physicians: vaccination during pregnancy.

Additional file 3. Table and figure. Detailed geographical distributions of respondents.

\section{Acknowledgements}

The authors wish to acknowledge the cooperation of the Korean Society of Maternal-Fetal Medicine, Korean Society of Perinatal Medicine, Korean Association of Obstetrics and Gynecology, and Korean Society of Ultrasound in Obstetrics and Gynecology. The authors would like to thank all participating women and healthcare professionals. We also thank the staff of Seoul St. Mary's Hospital (Mikyung Park and Yuri Jang) for their assistance in carrying out this survey and Prof. Yonggyu Park in the Department of Biostatistics, The Catholic University of Korea, for statistical review. 


\section{Authors' contributions}

Conceptualization: HSK, JHW; Data curation: BSK, HSK; Investigation: WJK, JHW, HSK; Methodology: HSK; Project administration: WJK, HSK; Resources: IYP, HSK; Supervision: HSK; Writing - original draft: BSK; and Writing - review \& editing: BSK, SHL, IYP, HSK.

All authors critically revised the article and gave approval of the version to be published.

\section{Funding}

This research was supported by a fund by the Research of Korea Centers for Disease Control and Prevention and The Catholic Medical Center Research Foundation in the program year of 2019. The funding bodies played no role in the design of the study and collection, analysis, and interpretation of data and in writing the manuscript.

\section{Availability of data and materials}

Derived data supporting the findings of this study are available from the corresponding author on request.

\section{Declarations}

\section{Ethics approval and consent to participate}

The Institutional Review Board of The Catholic University of Korea, Seoul St. Mary's Hospital approved the collection and use of clinical information for research purposes (KC19QES10646; Approval date, September 18, 2019). This study is in compliance with the 2013 Helsinki World Medical Association Declaration. The response to this survey implied their consent and written consent to participate was waived.

\section{Consent for publication}

Not applicable.

\section{Competing interests}

The authors declare that they have no competing interests.

\section{Author details}

'Department of Obstetrics and Gynecology, Seoul St. Mary's Hospital, College of Medicine, The Catholic University of Korea, Seoul, Republic of Korea. ${ }^{2}$ Department of Obstetrics and Gynecology, Eunpyeong St. Mary's Hospital, College of Medicine, The Catholic University of Korea, Seoul, Republic of Korea.

Received: 19 September 2020 Accepted: 7 July 2021

Published online: 16 July 2021

\section{References}

1. Neuzil KM, Reed GW, Mitchel EF, Simonsen L, Griffin MR. Impact of influenza on acute cardiopulmonary hospitalizations in pregnant women. Am J Epidemiol. 1998;148:1094-102. https://doi.org/10.1093/oxfordjournals. aje.a009587 PMID: 9850132.

2. Centers for Disease Control and Prevention (CDC). Maternal and infant outcomes among severely ill pregnant and postpartum women with,. pandemic influenza A (H1N1)-United States, April 2009-August 2010. MMWR Morb Mortal Wkly Rep. 2009;2011(60):1193-6 PMID: 21900872.

3. Choi WS, Choi MJ, Noh JY, Song JY, Kim WJ, Park DW, et al. Clinical and economic analysis of the 2009 H1N1 influenza pandemic among pregnant Korean women. Korean J Intern Med. 2019;34:1136-44. https://doi. org/10.3904/kjim.2017.107 PMID: 29232939.

4. Lafond KE, Nair H, Rasooly MH, Valente F, Booy R, Rahman M, et al. Global Role and Burden of Influenza in Pediatric Respiratory Hospitalizations, 1982-2012: A Systematic Analysis. PLoS Med. 2016;13:e1001977. https:// doi.org/10.1371/journal.pmed.1001977 PMID: 27011229.

5. Kim S, Moon HM, Lee JK, Rhie K, Yoon KW, Choi EH, et al. Changes in trends and impact of testing for influenza in infants with fever $<90$ days of age. Pediatr Int. 2017;59:1240-5. https://doi.org/10.1111/ped.13428 PMID: 28940983.

6. Chong CY, Yung CF, Gan C, Thio ST, Tan NW, Tee NW, et al. The burden and clinical manifestation of hospitalized influenza among different pediatric age-groups in the tropics. Influenza Other Respir Viruses. 2020;14:46-54. https://doi.org/10.1111/irv.12692 (PMID: 31608598).

7. Zaman K, Roy E, Arifeen SE, Rahman M, Raqib R, Wilson E, et al. Effectiveness of maternal influenza immunization in mothers and infants. N Engl J Med. 2008;359:1555-64. https://doi.org/10.1056/NEJMoa0708630 PMID: 18799552.

8. Omer SB, Clark DR, Aqil AR, Tapia MD, Nunes MC, Kozuki N, et al. Maternal Influenza Immunization and Prevention of Severe Clinical Pneumonia in Young Infants: Analysis of Randomized Controlled Trials Conducted in Nepal, Mali and South Africa. Pediatr Infect Dis J. 2018;37:436-40. https:// doi.org/10.1097/INF.0000000000001914 PMID: 29443825.

9. Centers for Disease Control and Prevention (CDC). Prevention and control of seasonal influenza with vaccines. Recommendations of the Advisory Committee on Immunization Practices--United States, 2013-2014. MMWR Recomm Rep. 2013; 62:1-43. PMID: 24048214

10. World Health Organization. Vaccines against influenza WHO position paper - November 2012. Wkly Epidemiol Rec. 2012;87:461-76 (PMID: 23210147)

11. World Health Organization. Meeting of the Strategic Advisory Group of Experts on immunization, April 2012-conclusions and recommendations. Wkly Epidemiol Rec. 2012;87:201-16 PMID: 24340402.

12. OECD (2021), Influenza vaccination rates (indicator). doi: https://doi.org/ 10.1787/e452582e-en. Accessed 30 Mar 2021

13. Korea Centers for Disease Control and Prevention. Guidelines of vaccination for adult. Chungbuk: Korea Centers for Disease Control and Prevention; 2019.

14. Jung EJ, Noh JY, Choi WS, Seo YB, Lee J, Song JY, et al. Perceptions of influenza vaccination during pregnancy in Korean women of childbearing age. Hum Vaccin Immunother. 2016;12:1997-2002. https://doi.org/10. 1080/21645515.2015.1119347 PMID: 27222241.

15. Ko HS, Jo YS, Kim YH, Park YG, Moon HB, Lee Y, et al. Knowledge, attitudes, and acceptability about influenza vaccination in Korean women of childbearing age. Obstet Gynecol Sci. 2015;58:81-9. https://doi.org/10.5468/ ogs.2015.58.2.81 PMID: 25798420.

16. Wilcox CR, Calvert A, Metz J, Kilich E, MacLeod R, Beadon K, et al. Determinants of Influenza and Pertussis Vaccination Uptake in Pregnancy: A Multicenter Questionnaire Study of Pregnant Women and Healthcare Professionals. Pediatr Infect Dis J. 2019;38:625-30. https://doi.org/10. 1097/INF.0000000000002242 PMID: 30418358.

17. Maertens K, Braeckman T, Top G, Van Damme P, Leuridan E. Maternal pertussis and influenza immunization coverage and attitude of healthcareworkers towards these recommendations in Flanders. Belgium Vaccine. 2016;34:5785-91. https://doi.org/10.1016/j.vaccine.2016.09.055 PMID: 27742214.

18. Praphasiri P, Ditsungneon D, Greenbaum A, Dawood FS, Yoocharoen P, Stone DM, et al. Do Thai Physicians Recommend Seasonal Influenza Vaccines to Pregnant Women? A Cross-Sectional Survey of Physicians' Perspectives and Practices in Thailand. PLoS ONE. 2017;12:e0169221. https://doi.org/10.1371/journal.pone.0169221 PMID: 28099486.

19. Kahn KE, Black CL, Ding H, Williams WW, Lu PJ, Fiebelkorn AP, et al. Influenza and Tdap Vaccination Coverage Among Pregnant Women - United States, April 2018. MMWR Morb Mortal Wkly Rep. 2018; 67:1055-1059. https://doi.org/10.15585/mmwr.mm6738a3 PMID: 30260946

20. European Centre for Disease Prevention and Control. Seasonal influenza vaccination and antiviral use in EU/EEA Member States - Overview of vaccine recommendations for 2017-2018 and vaccination coverage rates for 2015-2016 and 2016-2017 influenza seasons. Stockholm: ECDC; 2018.

21. Mak DB, Regan AK, Vo DT, Effler PV. Antenatal influenza and pertussis vaccination in Western Australia: a cross-sectional survey of vaccine uptake and influencing factors. BMC Pregnancy Childbirth. 2018;18:416. https:// doi.org/10.1186/s12884-018-2051-3 PMID: 30355329.

22. Noh JY, Seo YB, Song JY, et al. Perception and Attitudes of Korean Obstetricians about Maternal Influenza Vaccination. J Korean Med Sci. 2016;31(7):1063-8. https://doi.org/10.3346/jkms.2016.31.7.1063.

23. Wiley KE, Massey PD, Cooper SC, Wood NJ, Ho J, Quinn HE, et al. Uptake of influenza vaccine by pregnant women: a cross-sectional survey. Med J Aust. 2013;198:373-5. https://doi.org/10.5694/mja12.11849 PMID: 23581957. 
24. Paterson P, Meurice F, Stanberry LR, Glismann S, Rosenthal SL, Larson HJ. Vaccine hesitancy and healthcare providers. Vaccine. 2016;34(52):6700-6. https://doi.org/10.1016/j.vaccine.2016.10.042.

25. Napolitano F, Navaro M, Vezzosi L, Santagati G, Angelillo IF. Primary care pediatricians' attitudes and practice towards HPV vaccination: A nationwide survey in Italy. PLoS One. 2018;13(3):e0194920. Published 2018 Mar 29. doi:https://doi.org/10.1371/journal.pone.0194920

26. Leung SOA, Akinwunmi B, Elias KM, Feldman S. Educating healthcare providers to increase Human Papillomavirus (HPV) vaccination rates: A Qualitative Systematic Review. Vaccine X. 2019;3:100037. Published 2019 Aug 5. doi:https://doi.org/10.1016/j.jvacx.2019.100037

27. Korean statistical information service. Statistics on birth rate by region. Daejeon: Korean statistical information service; http://kosis.kr/ Accessed 10 Apr 2020.
28. Yeo Y, Gwack J, Kang S, Koo B, Jung SJ, Dhamala P, et al. Viral hepatitis and liver cancer in Korea: an epidemiological perspective. Asian Pac J Cancer Prev. 2013;14:6227-31. https://doi.org/10.7314/apjcp.2013.14.11.6227 PMID: 24377509.

29. Choe YJ, Yang JJ, Park SK, Choi EH, Lee HJ. Comparative estimation of Coverage between national immunization program vaccines and non-NIP vaccines in Korea. J Korean Med Sci. 2013;28:1283-8. https://doi.org/10. 3346/jkms.2013.28.9.1283 PMID: 24015031.

\section{Publisher's Note}

Springer Nature remains neutral with regard to jurisdictional claims in published maps and institutional affiliations.
Ready to submit your research? Choose BMC and benefit from:

- fast, convenient online submission

- thorough peer review by experienced researchers in your field

- rapid publication on acceptance

- support for research data, including large and complex data types

- gold Open Access which fosters wider collaboration and increased citations

- maximum visibility for your research: over 100M website views per year

At BMC, research is always in progress.

Learn more biomedcentral.com/submissions 